\title{
LA OBRA DEL MAESTRO DE CANTERÍA JUAN ÁLVAREZ (1544-1613) Y EL ARTE FUNERARIO EN LA CIUDAD DE PLASENCIA
}

\author{
ViCENTE MÉNDEZ HeRnÁN ${ }^{1}$ \\ Universidad de Extremadura
}

\begin{abstract}
El acuerdo inédito que toman en 1607 las clarisas placentinas de aceptar el patronazgo de don Rodrigo Calderón y su esposa doña Inés de Vargas y corresponderles con la ejecución de sus entierros y esculturas orantes para los que Juan Álvarez tenía ya dadas las trazas, ha permitido al autor poner en relación con este maestro los entierros que se hicieron en Plasencia entre 1596 y 1610/15.

Palabras clave: Juan Álvarez; escultura funeraria; siglos XVI-XVII; Plasencia.
\end{abstract}

\section{THE SCULPTURE OF MASTER STONEMASON JUAN ÁLVAREZ (1544-1613) AND FUNERARY ART IN THE CITY OF PLASENCIA}

The unprecedented agreement undertaken by the Poor Clares of Plasencia in 1607 to accept the patronage of Don Rodrigo Calderón and his wife Doña Inés Vargas, and in turn take charge of their funerals and the statues in attitude of prayer to which Juan Álvarez had already given shape, has allowed the author to link this master to the funerals held in Plasencia between 1596 and 1610/15.

Key words: Juan Alvarez; funerary sculpture; $16^{\text {th }}-17^{\text {th }}$ Centuries; Plasencia.

Cómo citar este artículo / Citation: Méndez Hernán, Vicente (2017): "La obra del maestro de cantería Juan Álvarez (1544-1613) y el arte funerario en la ciudad de Plasencia”. En: Archivo Español de Arte, vol. 90, núm. 359, Madrid, pp. 243-260. doi: 10.3989/aearte.2017.16

\section{Introducción}

Juan Álvarez (1544-1613) no es un maestro desconocido para la Historia del Arte. Ponz ${ }^{2}$ y Llaguno $^{3}$ ya dieron a conocer las primeras referencias sobre su trayectoria, que vinculaban a los canteros Pedro y su hijo Juan Ezquerra de Rozas a tenor de las obras que éstos iniciaron en el obispado de Plasencia, y Álvarez se encargó de concluir, como la iglesia de Malpartida o la escalera del aire en el convento placentino de Santo Domingo. En general, la historiografía posterior a Ponz y Llaguno ha girado en torno a las líneas maestras que éstos trazaron, y se ha centrado en las obras arquitectónicas donde Álvarez participó en calidad de arquitecto y maestro de

\footnotetext{
1 vicentemh@unex.es / ORCID iD: http://orcid.org/0000-0002-5060-6057

2 Ponz, 1778': 90-92, 114-115; 1784²: 184.

3 Llaguno, 1829: II, 53; III, 24-25.
} 
cantería. Sin embargo, y junto a esta faceta, nuestro artífice también ejerció en Plasencia como tracista y escultor al servicio de las más ilustres familias nobiliarias de la ciudad, que acudieron a su pericia para ver materializado el anhelo de alcanzar la vida eterna a través de la fama que les reportaba la confección de sus sepulcros y estatuas orantes.

El documento que nos ha permitido alumbrar esta nueva faceta del artista es una escritura relacionada con el patronazgo del convento placentino de Santa Clara, que don Rodrigo Calderón y Aranda (c.1576-1621), secretario de cámara de Felipe III y marqués de Siete Iglesias, y su esposa doña Inés de Vargas y Camargo (†1636), natural de Plasencia y señora de la Oliva, Grimaldo, Las Corchuelas y del castillo y villa de Monfragüe, reconocieron en 1605 para ratificar el mecenazgo que la familia de ésta ejercía sobre el monasterio. Por escritura otorgada el 1 de agosto de 1607, las clarisas aceptaron los 200 ducados de renta anual derivados del patronazgo y las condiciones de éste, entre las que se encontraba la obligación de hacer, "en la capilla mayor de la iglesia [...][,] dos nichos con bultos para sus entierros [...] conforme a la traza que Juan Álvarez y Miguel Sánchez tienen dada para ellos [...]"4. Es sabido que los marqueses determinaron finalmente enterrarse en el convento vallisoletano de Portaceli, y situar sus bultos orantes y los de don Francisco Calderón y doña María de Aranda Sandelín, padres de don Rodrigo, a ambos lados de la capilla mayor; fueron éstos un regalo del duque de Tursi, fabricados en los talleres de Génova probablemente por el escultor Taddeo Carlone (1543-1615)

Aunque las esculturas no se hicieron en Plasencia, el documento que otorgaron las clarisas nos permite profundizar en la actividad que Juan Álvarez y su colaborador desarrollaron como tracistas versados en las artes del dibujo; y precisar la intervención que Álvarez desarrolló en las obras con las que aparece relacionado documentalmente, como es el caso de la escritura que el obispo cauriense don Pedro de Carvajal otorgó el 1 de enero de 1610, para disponer lo tocante a su entierro en la iglesia placentina de San Nicolás. En dicho protocolo se hace referencia expresa a Juan Álvarez y a las trazas que había diseñado para construir el aledaño palacio CarvajalGirón a instancias del prelado ${ }^{6}$; dadas las relaciones artísticas que guarda la citada capilla con la casa solariega, es lícito pensar que don Pedro acudiera al maestro que ya tenía contratado a fin de encargarle también los diseños de su mausoleo y de la estatua orante que lo preside, que trazaría ayudado de "la caja y herramientas [...] de dibujar" que citaba en su testamento de 1613, según veremos.

Esta serie de precisiones nos conducen al siguiente aspecto a considerar en nuestra introducción. Las esculturas funerarias que actualmente se conservan en Plasencia, exceptuando la del obispo D. Pedro Ponce de León (1560-1573) que hiciera Francisco Giralte en 15737, fueron realizadas en un segmento temporal comprendido entre 1596 y 1610/15: en 1596 se hizo la escultura del coronel don Cristóbal de Villalba (1475-1516) para el convento de monjas terciarias de San Francisco, vulgo ildefonsas; en 1597 fallecía don fray Martín Nieto, bailío de la Orden de San Juan, cuyo sepulcro se emplazó en la capilla que poseía en el monasterio de Santo Domingo; y en 1610 debieron ultimarse los diseños para la citada sepultura de don Pedro de Carvajal, ejecutada entre ese año y el de 1615. Plasencia no era precisamente una ciudad pródiga en escultores que reunieran las dotes necesarias para tallar el mármol, de lo que es prueba evidente la obra que se le encargó a Giralte, y el contrato que firmó el cantero portugués Andrés Francisco en 1613 para ultimar la escultura de don Pedro de Carvajal, suscitado a tenor de la enfermedad que ya entonces debía padecer nuestro arquitecto, y a raíz de la cual falleció a finales de aquel mismo año. Los conjuntos funerarios señalados responden a unas trazas similares, y tienen rasgos estilísticos que entran en relación directa con la obra documentada de Juan Álvarez, a quien debieron acudir los precitados mecenas para ver ultimados sus deseos en materia de arquitectura y escultura funerarias. Este maestro estuvo además muy bien relacionado con la endogámica

${ }^{4}$ Archivo Histórico Provincial, Cáceres (AHPCC). Protocolos Notariales (PN), Plasencia, García Álvarez Oropesa, leg. 39 , ff. $1 \mathrm{v}-2 \mathrm{r}$.

5 Martín González, 1988: 284-285.

6 Pulido y Pulido, 1980: 57-58. AHPCC.PN, Cáceres, Juan Romero, leg. 4256, ff. 17r-20r.

7 Parrado del Olmo, 1981: 178. 
nobleza placentina a través del monasterio de Santo Domingo, en el que "han tomado el habito, y hecho profession, [...] muchos hijos de las muy nobles casas de Estremadura, [...] de los Marqueses de Mirabel, Condes de Torrejon, de los señores de Grimaldo, y de la casa de Monroy; [...] y de otras familias nobles de la ciudad"8. Los cargos que ocupó en Plasencia como maestro mayor de la misma y aparejador de su catedral, también avalan nuestra hipótesis al poner de manifiesto la pericia e importancia del artífice. Además, la evolución que desarrolla en su obra arquitectónica documentada corre en paralelo a la que advertimos en los sepulcros, tendentes a una mayor sobriedad decorativa que, por otro lado, justifica plenamente los elogios que Ponz hizo de los mismos 9 .

Todas las esculturas funerarias citadas responden al tipo orante que florece en el último tercio del siglo XVI, fruto, según ha analizado la profesora Redondo Cantera, del espíritu de la Contrarreforma, la inclinación hacia un creciente naturalismo que hiciera visibles los rasgos del difunto, y por la influencia de la obra de artistas como Pompeyo Leoni ${ }^{10}$. De igual modo, en los sepulcros placentinos se advierte la pérdida de la minuciosidad y el detallismo que fueron característicos de la etapa anterior, y cómo se continuó demandando el modelo que Francisco Giralte había introducido en la ciudad.

\section{Datos biográficos y trayectoria como arquitecto}

Juan Álvarez nació en 1544, fecha deducible de los 34 años que tenía cuando fue reclamado en 1578 para que ejerciera su cargo de aparejador en la catedral de Plasencia, y reparara "la fuente vieja" de la plaza a la que abre el brazo meridional del crucero ${ }^{11}$. Sin embargo, su nombre no figura en el contexto artístico cacereño hasta 1574, y lo hace vinculado al entorno de Pedro Ezquerra de Rozas, arquitecto oriundo del País Vasco ${ }^{12}$, aunque natural de Ojébar (Cantabria) ${ }^{13}$, que debió llegar a Plasencia hacia mediados del siglo XVI atraído por la obra de la catedral que ejecutaba Rodrigo Gil de Hontañón, y por la fábrica de algunos de los templos que entonces se renovaban en la provincia ${ }^{14}$. Su muerte en $1561^{15} \mathrm{y}$, sobre todo, la creciente actividad que empezó a desarrollar su hijo Juan Ezquerra de Rozas, también maestro de cantería, después de ingresar en el equipo de canteros de El Escorial (1568-1579) ${ }^{16}$ y profesar en la Orden de predicadores -en 1571 ya figura como administrador del convento salmantino de San Esteban ${ }^{17}$-, fueron las circunstancias que llevaron a Juan Álvarez a tomar bajo su dirección las iglesias que aquéllos tenían emprendidas, a saber, Malpartida de Plasencia (desde 1574) ${ }^{18}$ y Miajadas ${ }^{19}$, y que a partir de entonces iniciara una trayectoria en solitario que terminaría convirtiéndole en uno de los artífices más importantes de las últimas décadas del siglo XVI e inicios del XVII.

En cuanto a su origen, cabe la posibilidad de pensar que Juan Álvarez fuera hijo del homónimo cantero documentado en Plasencia en 1550 y $1557^{20}$, y que de algún modo se hubiera

\footnotetext{
8 Fernández, 1627: 112.

9 Ponz, 17781: 110-112 (sepulcros de D. Pedro y el coronel) y 113-114 (bailío).

10 Redondo Cantera, 1987: 127-128.

11 Biblioteca del Seminario Mayor de Plasencia (BSMP), Apuntes de José Benavides Checa (AJBCh), Artistas. Juan Álvarez, 1578.

12 Barrio Loza/Moya Valgañón, 1981: 212.

13 Ponz, 17781: 90. González Echegaray/Aramburu-Zabala/Alonso Ruiz/Polo Sánchez, 1991: 212.

14 Sánchez Lomba, 1994: 81.

15 González Echegaray/Aramburu-Zabala/Alonso Ruiz/Polo Sánchez, 1991: 212.

16 Su trabajo se documenta en los años 1568, 1572, 1574, 1578 y 1579. Andrés, 1972: 16, 26-27, 40, 68, 71 y 77. Entre 1569 y 1576 se cita como "destajero del cuarto de la librería y sacristía de San Lorenzo". Prieto Cantero, 1963: 33-34.

17 Rodríguez G. de Ceballos, 1987: 37.

18 Ponz, 17781: 89-92. Llaguno, 1829: III, 25. Benavides Checa, 1907: 130-131. Montero Aparicio, 1977: 189.

19 Ponz, 17842: 184-185. Llaguno, 1829: III, 25. Sánchez Lomba/García Bacas, 1988: 43, 48.

20 BSMP, AJBCh, Artistas. Juan Álvarez.
} 


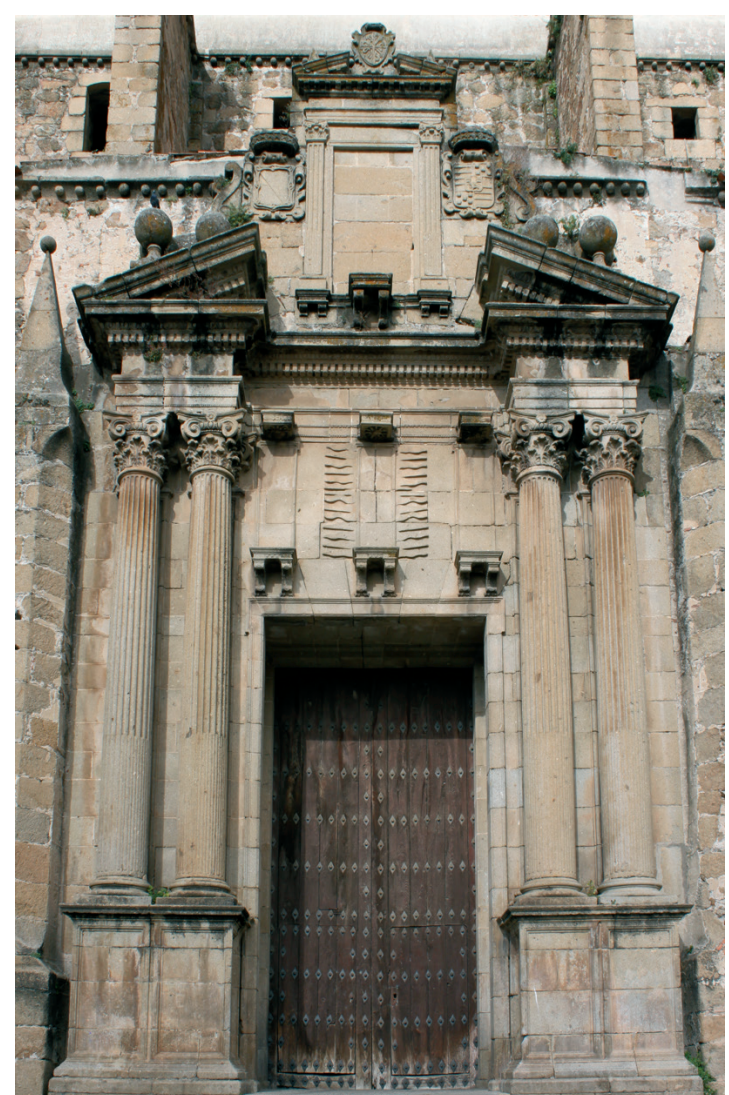

Fig. 1. Plasencia, iglesia del convento de Santo Domingo, portada de ingreso por el brazo sur del crucero. Trazas de Juan Álvarez, finales del siglo XVI.

vinculado a la cuadrilla de los Ezquerra aprovechando que Pedro ya figuraba como vecino de la ciudad en $1550^{21}$, habida cuenta además que no volvemos a tener noticias de su posible ascendiente después de las fechas precitadas. Ignoramos si existía parentesco con el también homónimo maestro de obras avecindado en Rubielos de Mora (Teruel) a mediados del siglo XVI, y de origen vizcaíno ${ }^{22}$; sin embargo, la coincidencia es lo suficientemente sugerente como para no descartar al menos una posible ascendencia norteña de los Álvarez extremeños, que habrían seguido el camino de otros tantos maestros de similar procedencia a lo largo de la centuria ${ }^{23}$.

Cuatro años después de tomar la obra del templo malpartideño bajo su maestría, Juan Álvarez se hacía cargo de terminar la escalera del aire para el convento dominico de San Vicente, en Plasencia; el contrato se firmó en noviembre de 1578, y en él se comprometió a "hazer y acabar vna escalera [...] que esta començada a haçer junto a la sacristía [...]"24. La influencia del ya entonces padre fray Juan Ezquerra debió ser decisiva para que la congregación confiara en Álvarez como continuador de una obra, cuyo inicio es lícito pensar que dirigiera el dominico hasta que se viera obligado a abandonarlo por las muchas necesidades de su Orden ${ }^{25}$. Por tal motivo, el nombre de Juan Álvarez es el que figura en la inscripción situada en el muro oriental de la escalera, sobre uno de los arcos y junto al año 1577 en que debió principiar la construcción. La

21 Pulido y Pulido, 1980: 144

22 Martínez Verón, 2000: 26.

23 Navareño Mateos/Sánchez Lomba, 1989: 7-13.

24 Pescador del Hoyo, 1959: 401.

25 Benavides Checa, 1907: 157-158. Pescador del Hoyo, 1959: 400. En 1571, 1581, 1590 y 1599 se documenta en el convento salmantino San Esteban (Rodríguez G. de Ceballos, 1987: 37, 44-45 y 48. Beltrán de Heredia, 1972: 599). 
singularidad de la obra reside en el diseño del último tramo de subida -de los tres perpendiculares-, al funcionar como un arco carpanel de amplia luz cuyos empujes descarga longitudinalmente.

La escalera mereció los elogios de los cronistas de la Orden y también de fray Alonso Fernández (1573-1633), historiador, predicador general de los dominicos y fraile profeso en el convento de Plasencia ${ }^{26}$, lo que justifica el hecho de haber elegido también a Alvarez como maestro encargado de hacer la portada meridional del cuerpo eclesial. La atribución parte de $P^{P o n z} z^{27}$, y se documenta a partir del contrato que Alonso Sánchez suscribió el 27 de junio de 1622 para elevar el segundo cuerpo ${ }^{28}$; si consideramos la referencia que Álvarez hacía a este cantero en el testamento que otorgó el 13 de diciembre de 1613, donde le menciona como su "criado" 29 , es lógico pensar que los dominicos encomendaran su terminación al aprendiz de quien había trazado el conjunto de la portada (fig. 1). Es evidente la similitud que guarda esta obra con el primer cuerpo de la fachada que cierra a poniente la iglesia de Malpartida de Plasencia; ambos ingresos llevan sus vanos moldurados, y responden a un modelo que el maestro utilizó también para diseñar los sepulcros de los próceres de la más alta alcurnia placentina, donde el arcosolio va enmarcado entre parejas de columnas o pilastras clásicas, sobre las que asienta un arquitrabe que sirve de apeo, en el caso del sepulcro del obispo Carvajal en San Nicolás, para un frontón partido que abraza las armas del finado. Es evidente además que se trata de un tipo de arquitectura donde se materializa el giro clasicista que Álvarez introdujo en la zona a fines del siglo XVI, no exenta de fórmulas novedosas para la provincia como la cúpula elíptica que veremos en la capilla de don Pedro de Carvajal.

La Orden de predicadores no solo debió abrirle las puertas de sus patronos a Juan Álvarez, sino que también le tuvo en la suficiente estima como para encomendarle la obra del cimborio del convento salmantino de San Esteban en $1601^{30}$. De la importancia que el maestro llegó a tener en el contexto arquitectónico del momento, son fiel reflejo su nombramiento como aparejador de la catedral placentina en agosto de 1574, con una asignación no superior a 8.000 maravedís anuales ${ }^{31}$, y los encargos que recibió para supervisar las obras del obispado, como fue el reconocimiento que hizo en 1594 de uno de los arcos de la iglesia de Serrejón ${ }^{32}$; citemos también el cargo de maestro mayor de las obras de la ciudad de Plasencia que desempeñó ${ }^{33}$; o el hecho de haber sido convocado a Madrid en 1610 para presentar un proyecto destinado a la construcción del noviciado de los jesuitas, donde figura nominado como "maestro mayor de las obras de la Yglesia de Plasencia y Salamanca", y que firmó con Francisco y Joaquín Grajal, Juan Bautista Monegro y el jesuita Juan Soler ${ }^{34}$. Esta referencia hace posible intuir al menos una conexión con el entorno escurialense y justificar la entrada del clasicismo en Plasencia.

Juan Álvarez pudo desarrollar esta intensa actividad profesional merced a una amplia cuadrilla de aprendices y oficiales. Entre los primeros se encontraban Alonso Sánchez, a quien cita en su testamento para dejarle "la caja y herramientas [...] de dibujar"; su "criado Blas" González (doc. 1615-1625), que también menciona en sus últimas voluntades ${ }^{35}$; y Juan Moreno, vecino de Plasencia y residente en Salamanca, litigante en el pleito que Álvarez le puso en 1613 por ausen-

${ }^{26}$ López, 1613: 193, donde señala que es "vna escalera de singular traça”, -y añade Fernández, 1627: 109_ "auiendo vn transito debaxo de vn arco donde estriua toda ella, que causa admiracion a los que la vèn".

27 Ponz, $1778^{1}: 115$.

28 AHPCC.PN, Plasencia, Francisco de Campo, leg. 242, s.f. Alonso Sánchez firmó el contrato junto a los canteros Antonio Suárez y Juan de Ruesga.

29 AHPCC.PN, Plasencia, Pedro González Cidoncha, leg. 1068, s.f.

30 Rodríguez G. de Ceballos, 1987: 48-50.

31 Benavides Checa, 1907: 119, 127. Archivo Capitular de Plasencia (ACP), Libro de Acuerdos Capitulares n. ${ }^{\circ} 13$ (1566-1575), ff. 433v y 444v, 27 y 30 de agosto de 1574, respectivamente.

32 Archivo Parroquial de Serrejón, Libro de Cuentas de Fábrica, 1593-1595, cuentas de 1594; por su trabajo recibió 1.122 maravedís.

33 Pulido y Pulido, 1980: 57. AHPCC.PN, Plasencia, Juan Romero, leg. 4256, f.18v.

34 Rodríguez G. de Ceballos, 1968: 250-251.

35 AHPCC.PN, Plasencia, Pedro González Cidoncha, leg. 1068, s.f. 
tarse de su casa ${ }^{36}$, y a quien es posible identificar con el conocido arquitecto salmantino protobarroco, del que existía además un lapso de quince años sin constancia documental (1597$1612)^{37}$. Entre sus oficiales estaban el cantero Sebastián Rodríguez ${ }^{38}$; y también debió formarse en esta cuadrilla el ya citado Miguel Sánchez (doc. 1603-1617).

A su vez, de tan amplia actividad se derivaron los pingües beneficios que vemos reflejados en el testamento del arquitecto, quien no escatimó a la hora de dar en dote a cada una de sus dos hijas la importante suma de 1.000 ducados; eran aquéllas Isabel Álvarez y Ana Mateos, fruto de su matrimonio con la entonces ya difunta María Mateos. De su buena posición en la ciudad también es indicio el enlace entre la citada Isabel y el escribano de rentas Antonio Hernández; y de la estima que gozaba en su profesión, el informe que hizo en 1587 en el proceso judicial que estaba abierto contra el cantero Diego González a raíz de las obras de la fortaleza de Moraleja $(\text { Cáceres })^{39}$, en el que declaró a favor de éste ${ }^{40}$.

\section{Moradas de eternidad. Un maestro al servicio de la nobleza placentina}

\section{Los sepulcros del convento dominico de San Vicente}

La estrecha colaboración que Juan Álvarez estableció con los Ezquerra pronto se tradujo en la confianza que depositaron en él tanto los dominicos como los patronos del monasterio. Desde su fundación en $1477^{41}$, los duques de Plasencia tenían reservada la capilla mayor y zona del crucero para disponer sus entierros y los de su linaje, según se desprende del testamento que don Álvaro de Zúñiga (†1488) otorgó el 21 de julio de 1486, y de la "noble e rica sepultura con su bulto de alabastro" que dispuso construir flanqueada por los de su primera y segunda esposas, doña Leonor Manrique († c.1455) y doña Leonor Pimentel $(\dagger 1486)^{42}$ respectivamente. Aunque las mandas testamentarias relativas a este particular parece ser que no se llevaron a $\mathrm{cabo}^{43}$, la familia mantuvo la propiedad que tenía sobre la capilla mayor, donde recibió sepultura en 1533 don Juan de Zúñiga y Pimentel (1459-1504), último maestre de la Orden de Alcántara, arzobispo y cardenal de Sevilla e hijo de don Álvaro de Zúñiga y de su segunda esposa ${ }^{44}$.

Lo mismo sucedió con las capillas del crucero, pertenecientes ya durante el siglo XVI a los estados de Mirabel, marquesado que obtuvo la rama placentina de los Zúñiga en $1535^{45}$. Doña María de Zúñiga Manuel y Sotomayor, II marquesa de Mirabel, dispuso su enterramiento y el de su esposo en dichas capillas a finales del siglo XVI. Estaba casada con su deudo don Luis de Ávila y Zúñiga, gentilhombre de cámara de Carlos V, embajador en Roma, general de los ejércitos imperiales y de la caballería española, comendador mayor de Alcántara y consejero de guerra y de estado de Felipe II, a cuya muerte fue enterrado en la capilla situada al lado del Evangelio, en la sepultura que se documenta a partir de 1507, y hasta 1813. Según reza en el epitafio que aún se conserva en la pared de dicha capilla, el II marqués de Mirabel (†1573) fue enterrado junto a sus antepasados en la tumba que mandó construir su mujer en 1589. Debía ser un sepulcro tumular exento, realizado con "losas de jaspe" y sustentado por los seis leones que

\footnotetext{
${ }^{36}$ AHPCC.PN, Plasencia, Pedro González Cidoncha, leg. 1068, s.f., 21 de diciembre de 1613.

37 Rodríguez G. de Ceballos, 1976: 251.

38 AHPCC.PN, Plasencia, Pedro González Cidoncha, leg. 1068, s.f., 1 de diciembre de 1613.

39 Navareño Mateos, 1988: 21. AHN. Archivo Judicial de las Órdenes Militares (AJ.OO.MM.), pleito n. ${ }^{\circ}$ 28.690, s.f.

40 AHN.AJ.OO.MM., pleito n. ${ }^{\circ} 28.690$, s.f.

${ }^{41}$ López, 1613: 193.

42 Paredes y Guillén, 1909: 91-92.

43 Fernández, 1627: 116. Paredes y Guillén, 1909: 119-120.

44 Fernández, 1627: 116.

45 Cadenas y López/Barredo de Valenzuela y Arrojo, 2003: 161.
} 
hoy sirven de apeo a las citadas losas y también a la inscripción, situadas en la actualidad sobre la pared del muro del crucero; originalmente, la tumba iba rodeada con su reja ${ }^{46}$.

Doña María de Zúñiga se reservó la capilla situada al lado de la Epístola para "hacer su retablo y entierro, poner verja, arcos, cerrar puertas y otras cosas" 47 . Según las cuentas que sus testamentarios ofrecieron el 24 de junio de 1605, sabemos que el retablo se hizo ${ }^{48}$, y que Juan Álvarez fue el encargado de ejecutar el "tunbulo" para el entierro en 1596, fecha de una libranza a su favor por valor de 5.000 maravedís en concepto del salario de un año ${ }^{49}$. La familia de los Zúñiga debía conocer muy bien al maestro, pues incluso se baraja su probable intervención en las obras del palacio de Mirabel, paredaño al monasterio ${ }^{50}$. El túmulo se concibió como un panteón familiar -según el dominico fray Alonso Fernández, "la Capilla Colateral de la Epistola es entierro para los Marqueses de Mirabel" 51 , de lo que se deduce que los restos mortales de don Luis de Ávila y Zúñiga fueron trasladados a este nuevo emplazamiento-, dotado de la cripta que hoy cubren dos losas de bronce, ejecutadas con posterioridad a la obra referida ${ }^{52}$ para tratar de paliar los destrozos que ocasionaron los franceses en el templo, del que prácticamente desaparecieron todos los ornamentos ${ }^{53}$. El conjunto original se complementaba con los cincuenta y dos escudos de armas que el pintor placentino Juan de Quintana se encargó de policromar ${ }^{54}$.

Esta obra de Juan Álvarez apenas si es apreciable hoy día, pero la referencia a su intervención en el túmulo de los marques de Mirabel nos permite vincularle con otro de los enterramientos que se hicieron de forma contemporánea en la iglesia del convento. Se trata del sepulcro de don fray Martín Nieto (†1597), bailío de la Orden de San Juan de Malta, comendador de las Nueve Villas de Campos y Los Yébenes, cuya sepultura dispuso ubicar en la capilla que su padre don Fernán Nieto de Trejo le compró a don Pedro Varona en 1594 -contigua a la de los marqueses y advocada al Bautista y a Santo Tomás de Aquino ${ }^{55}$-, con la expresa condición de poder "abrir en la pared que cae en la calle un lucillo con su arco para que en él se enterrase tan solamente el dicho Sr. Baylio [...]" ${ }^{56}$. La calidad y el clasicismo de la obra llamaron la atención de Ponz, quien la recogió en su Viage de España con una detallada descripción:

En la capilla de S. Juan se ve un magnífico sepulcro, y consiste principalmente en un nicho adornado de dos columnas corintias á cada lado. Sobre la urna hay una estatua de rodillas executada en marmol, y con armadura, de lo mas excelente que yo he visto en España, desde que renacieron las bellas artes; llena de gracia, grandiosidad, y expresion, de suerte que manos, y cabeza parecen obra de los antiguos griegos. $[\ldots]^{57}$

El mausoleo sobrevivió a la Guerra de la Independencia, aunque los graves daños que los franceses perpetraron en el convento también afectaron a la escultura del titular, que fue terriblemente mutilada $^{58}$; solo perduran el tronco, las piernas y los almohadones sobre los que se arro-

\footnotetext{
46 Mélida y Alinari, 1924: II, 319. López Martín, 1993: 327-328 y 349-350.

47 López Martín, 1993: 328.

48 Méndez Hernán, 2004: 327-328.

49 AHPCC.PN, Plasencia, Francisco de Campo, leg. 232, s.f. También consta otro pago de 26 reales por obras menudas relacionadas con el túmulo.

${ }^{50}$ Mélida y Alinari, 1924: II, 330.

51 Fernández, 1627: 113.

52 Sobre ella consta el título de marqueses de Mirabel, y el de condes de Berantevilla que Felipe IV creó en 1624 por favor de Enrique de Zúñiga y Dávila. Cadenas y López/Barredo de Valenzuela y Arrojo, 2003: 161.

${ }^{53}$ Según se recoge en la carta que el prior José M. ${ }^{a}$ Ramos Monroy remitió el 28 de noviembre de 1809 a la Junta Central Suprema Gubernativa del Reino informando sobre los destrozos causados por la francesada. AHN.Estado, leg. 27, exp. 276, f. 2 v.

54 Méndez Hernán, 2004: 328.

55 Fernández, 1627: 114.

56 Lobo, 2008: 8, 18.

57 Ponz, 1778: 113.

58 En 1809, el prior refería que fueron "sus imagenes unas quemadas, y otras mutiladas, ó destrozadas del todo". AHN.Estado, leg. 27, exp. 276, f. 2v.
} 
dilla ${ }^{59}$, todo ejecutado en una sola pieza. A finales del siglo XIX, el conjunto funerario se cubrió con el retablo neogótico que aún hoy nos impide contemplar el entierro ${ }^{60}$ (fig. 2), y la escultura se situó en el recinto que sirve de acceso a la sacristía, donde Mélida pudo verla ${ }^{61}$; en la actualidad, se exhibe a la entrada del Parador Nacional de Turismo, que ocupa las antiguas dependencias monacales (fig. 3).

Según consta en el epitafio situado delante de la urna (fig. 4) ${ }^{62}$, fray Martín cumplió en todo punto las estipulaciones que se fijaron con motivo de la compra de su capilla en 1594, fecha que nos sirve para datar la obra y llevarla hasta el 29 de julio de 1597, en que fallece. Dichas condiciones le obligaban a costear el retablo de los santos titulares al que se alude en la inscripción, y a cubrir con una vidriera la ventana que daba a la calle. Para la obra del sepulcro, el bailío debió recurrir a Juan Álvarez, maestro asiduo en el convento y hombre de confianza para los dominicos y sus patronos; recordemos que un hermano del bailío, fray Jerónimo Nieto, también había profesado en la Orden ${ }^{63}$, y debía conocer en primera persona el buen hacer del arquitecto y el aprecio que éste gozaba en la congregación. Asimismo, la carrera militar de fray Martín, quien asistió en 1565 a la defensa de la isla de Malta contra los turcos, o la de su familia, con dos hermanos "que murieron en Italia en las guerras del Emperador contra Francia"64, es de rigor vincularla a la trayectoria militar y a los importantes cargos que desempeñó don Luis de Ávila y Zúñiga, II marqués de Mirabel y hombre de confianza de Carlos V, quien precisamente se había distinguido en Viena durante la guerra contra los Turcos en 1532, y después en Túnez (1535), Provenza (1537) y los Países Bajos $(1543)^{65}$. Es de imaginar que un destacado miembro del linaje de los Nieto-Trejo quisiera reposar junto a quien había compartido con él similares objetivos en el campo militar, y que acudiera al artista que en esos momentos se ocupaba de hacer el mausoleo de su familia en la misma iglesia donde había dispuesto su última morada, paredaña a la suya.

Otra serie de relaciones podemos establecer en el seno de la familia Nieto para apoyar nuestra hipótesis sobre la autoría de Juan Álvarez. Recordemos que doña María Nieto de Solís, sobrina de fray Martín, estaba casada con su primo Rui González de Carvajal ${ }^{66}$, y que de este matrimonio nació don Diego Esteban González de Carvajal Nieto ${ }^{67}$, regidor perpetuo de Plasencia - ciudad de la que Álvarez era maestro mayor- y señor de la casa de Carvajal, cuyas casas en la calle de Trujillo -hoy palacio Carvajal-Girón- Álvarez trazaría en 1610 a instancias del obispo cauriense don Pedro de Carvajal, hermano del precitado Rui González de Carvajal; así lo declaraba el mismo don Pedro cuando dispuso lo tocante a la capilla funeraria que había previsto construirse en San Nicolás ${ }^{6}$. De todo ello se desprende que Juan Álvarez se había convertido en un artífice al servicio de la familia Carvajal, y de la rama que los vinculaba con los NietoTrejo ${ }^{69}$.

Las relaciones formales entre el sepulcro y la obra documentada del artista también apoyan nuestra hipótesis. Se trata de un entierro en arcosolio flanqueado por las dos columnas corintias que describía Ponz, sobre las que apea un arquitrabe decorado a base de dentículos y ovas y

\footnotetext{
59 Rosado, 1906: 68, donde afirma que "la cabeza y manos [...] se dice que se las llevaron los franceses".

${ }^{60}$ Lobo, 2008: 9.

${ }^{61}$ Mélida y Alinari, 1924: II, 320.

62 "AQVI YAZE DON MIN NIETO BAILIO DE LAS NV/EVE VILLAS COMENDADOR DE LA VILLA I ENCOMI/ENDA DE YEVENES EL QVAL DOTO ESTA CAPI/LLA Y LA CAPELLANIA QVEN ELLA ESTA FVNDA/DA I TODOS SANTOS Y HIZO ESTE RETABLO Y ESTE / ENTIERO ES SV VOLUNTAD QVE NO SE A/ BRA PARA OTRA PERSONA NINGVNA FALLECIO / A VEINTE Y NUEVE DE IVLUIO DE MILL Y / QVINIENTOS Y NOVENTA Y SIETE AÑOS".

${ }^{63}$ Fernández, 1627: 100.

64 Fernández, 1627: 100-101.

65 Mateos Calvo, 2015: 14.

${ }^{66}$ Fernández, 1627: 100.

67 López de Haro, 1622: I, 393.

${ }_{68}$ Pulido y Pulido, 1980: 57. AHPCC.PN, Cáceres, Juan Romero, leg. 4256, ff.17r, 18v

${ }^{69}$ Los parentescos en López de Haro, 1622: I, 393. Fernández, 1627: 39-40, 100-101.
} 


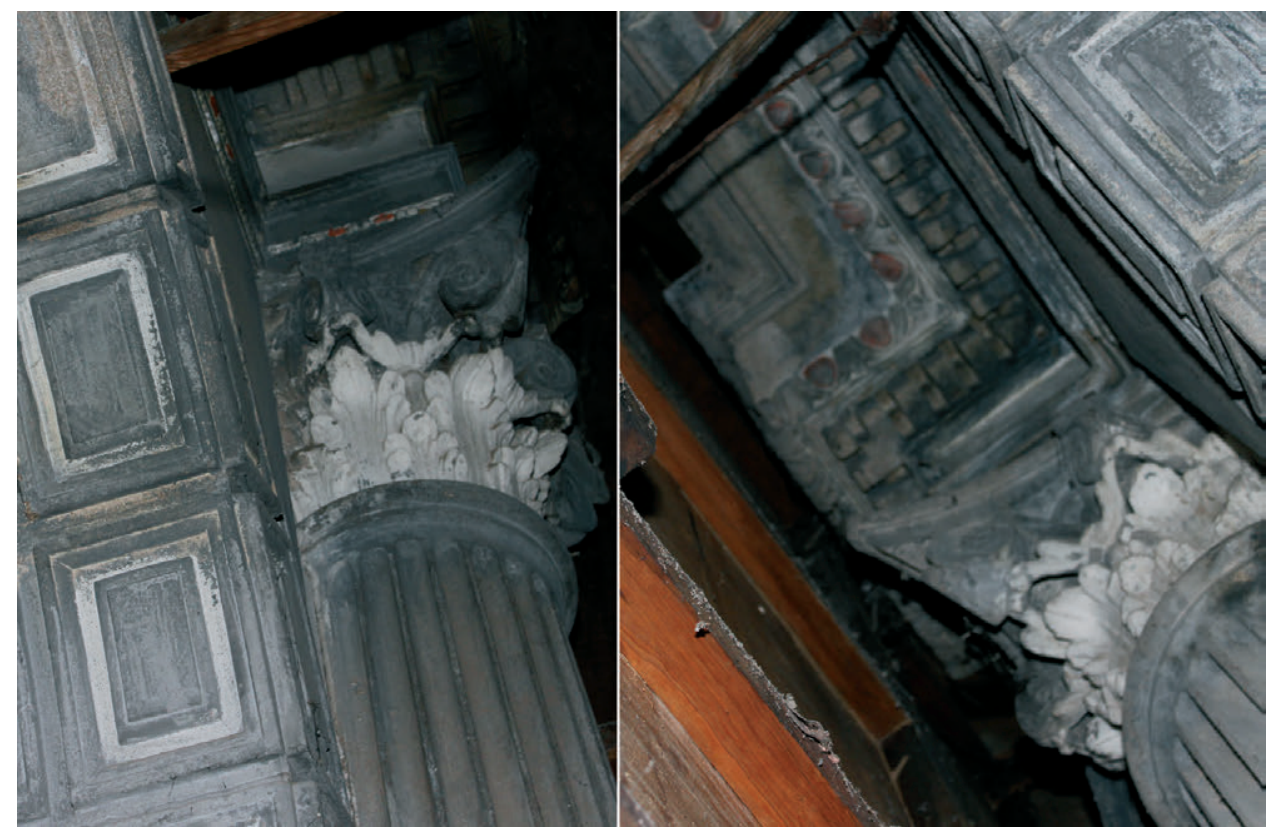

Fig. 2. Plasencia, iglesia del convento de Santo Domingo, detalle del sepulcro de don fray Martín Nieto $(\dagger 1597)$, cubierto en la actualidad por un retablo neogótico.

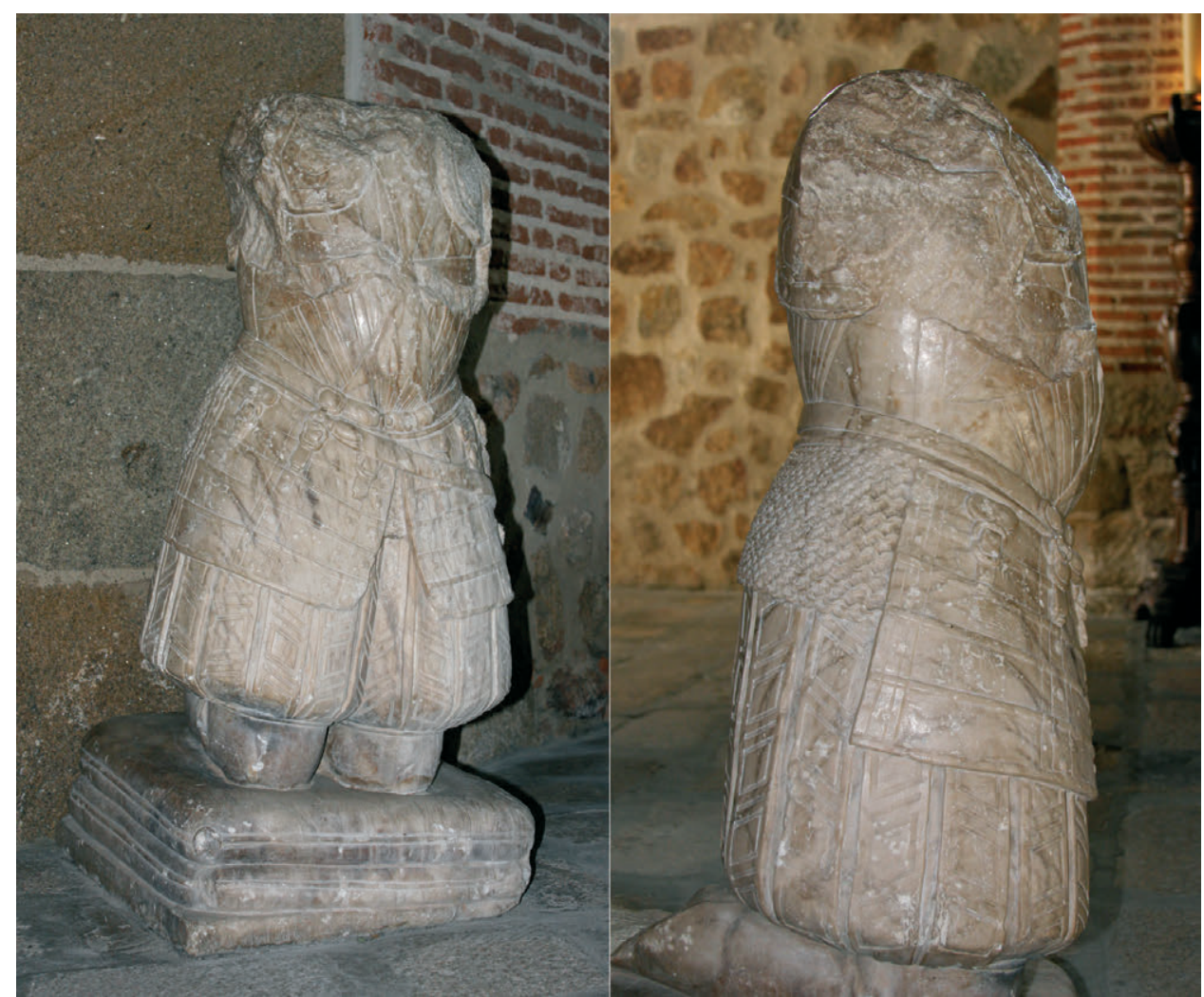

Fig. 3. Escultura funeraria de don fray Martín Nieto ( $† 1597)$, bailío de la Orden de San Juan de Malta, originalmente situado en su sepulcro de la iglesia del convento de Santo Domingo en Plasencia (fig. 2). Actualmente preside el acceso al Parador Nacional de Turismo. Imagen general y detalle de perfil. 


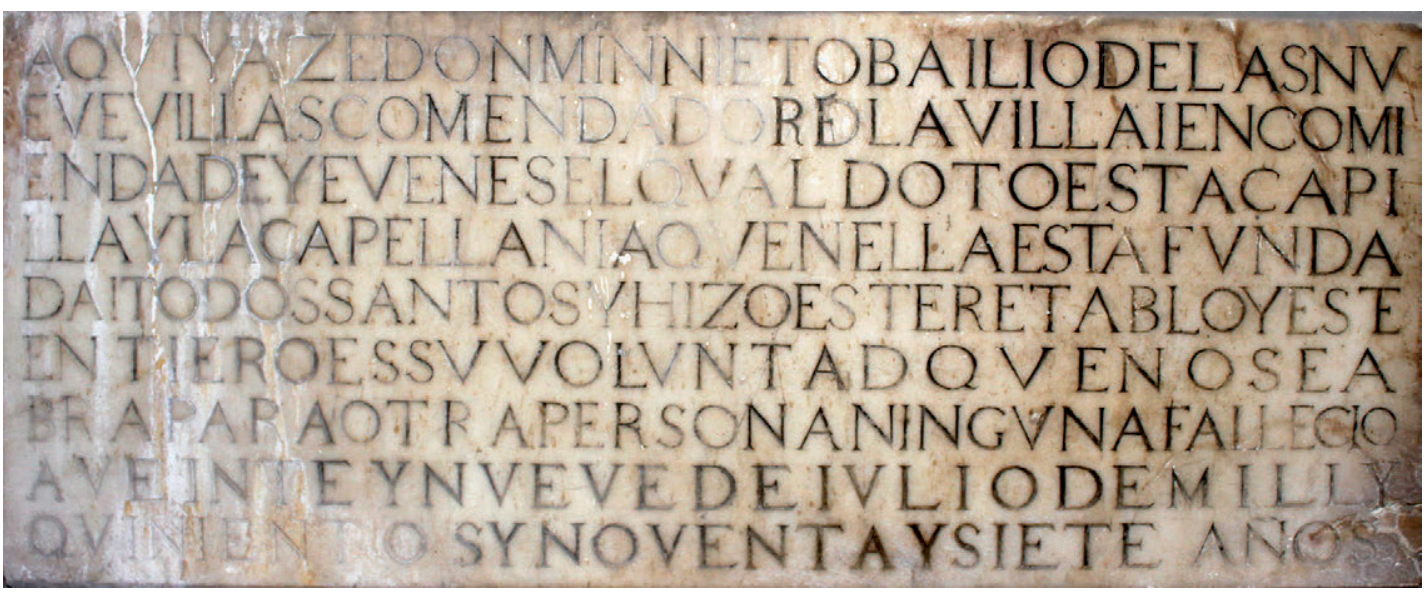

Fig. 4. Plasencia, iglesia del convento de Santo Domingo, epitafio del sepulcro de don fray Martín Nieto $(† 1597)$.

flechas. La traza clasicista del mausoleo es similar a la que Juan Álvarez diseñó para la portada meridional del templo dominico, con la que guarda además plena correspondencia en cuanto a los motivos decorativos. El conjunto funerario descrito alberga en su interior el arcosolio y la urna sobre la que iba situada la escultura de fray Martín, con el epitafio situado sobre el frente de aquélla. Dicho arcosolio abre en medio punto y se flanquea con pilastras toscanas cajeadas, similares a las que el maestro utilizará en el patio del citado palacio Carvajal-Girón, y a las que trazará en el ingreso a la capilla funeraria del obispo don Pedro de Carvajal. Un juego de molduras y casetones orna el intradós del arco, rematado con una cartela de cueros recortados en la que se lee la inscripción "EXPECTO DONEC VENIAT IMMVTATIO MEA JOB 14", alusiva a una profecía del mensaje de la resurrección y frecuente en este tipo de obras ${ }^{70}$.

A pesar de los graves deterioros que sufrió la escultura del finado, aún se aprecia el detallismo de su labra: ciñe media armadura, con peto decorado con la cruz de Malta, y espaldar, además de la escarcela y cota de malla; viste calzas y gregüescos acuchillados. Se representa de rodillas sobre almohadones, fruto de la actitud orante en la que debía ir representado. Es similar a la figura del coronel don Cristóbal de Villalba, tallada de forma contemporánea a la del bailío, situado también sobre urna funeraria y englobado originalmente bajo una estructura arquitectónica de la que nos han llegado breves noticias.

\section{El sepulcro del coronel don Cristóbal de Villalba (1475-1516)}

El conjunto funerario del coronel Villalba (figs. 5 y 6) está situado en la capilla mayor del convento placentino de San Ildefonso, donde fue instalado en 1596 -según reza en la inscripción ${ }^{71}$ - por su hijo don Pedro Bermúdez ${ }^{72}$. Nacido en el seno de una familia de hidalgos placentinos, los triunfos militares de don Cristóbal -I expedición a Italia (1494-1498)- pronto se vieron recompensados con los nombramientos de coronel y caballero santiagués que le concedió el rey Católico, además de su adscripción a la Corte del monarca (1503), y de un ventajoso matrimonio

\footnotetext{
70 "Espero mientras llega mi transformación", Job 14, 14. Lobo, 2008: 10, nota 23.

${ }^{71}$ Mélida y Alinari, 1924: II, p. 317; el año apenas si es hoy perceptible.

72 Fernández, 1627: 179.
} 


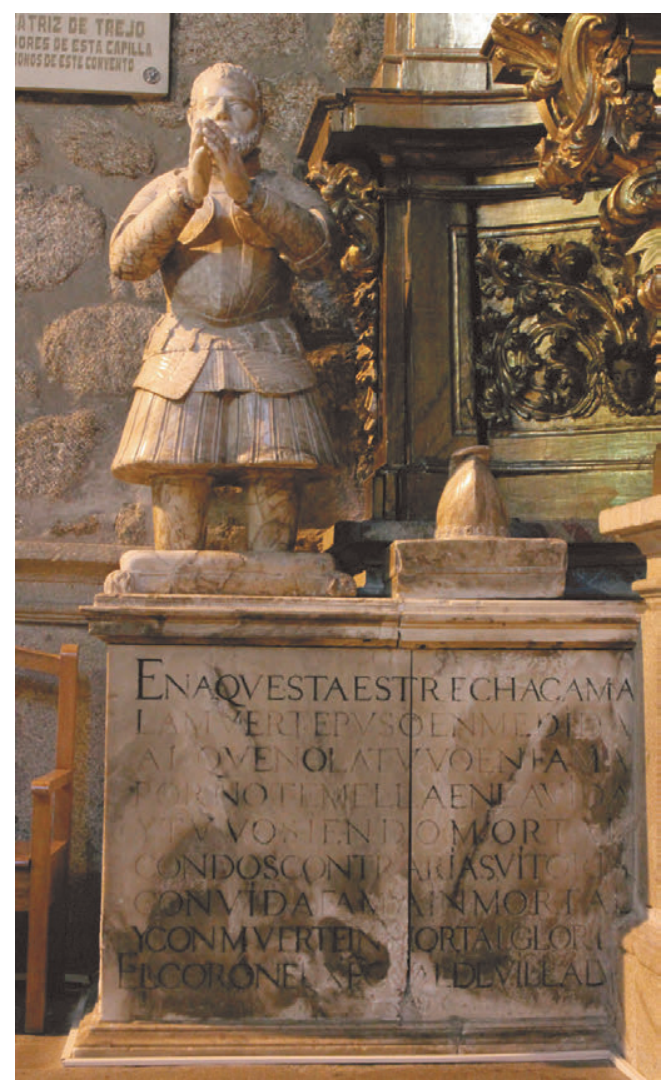

Fig. 5. Plasencia, convento de San Ildefonso, sepulcro del coronel don Cristóbal de Villalba $(† 1516)$, realizado en 1596. Vista general del conjunto actual.

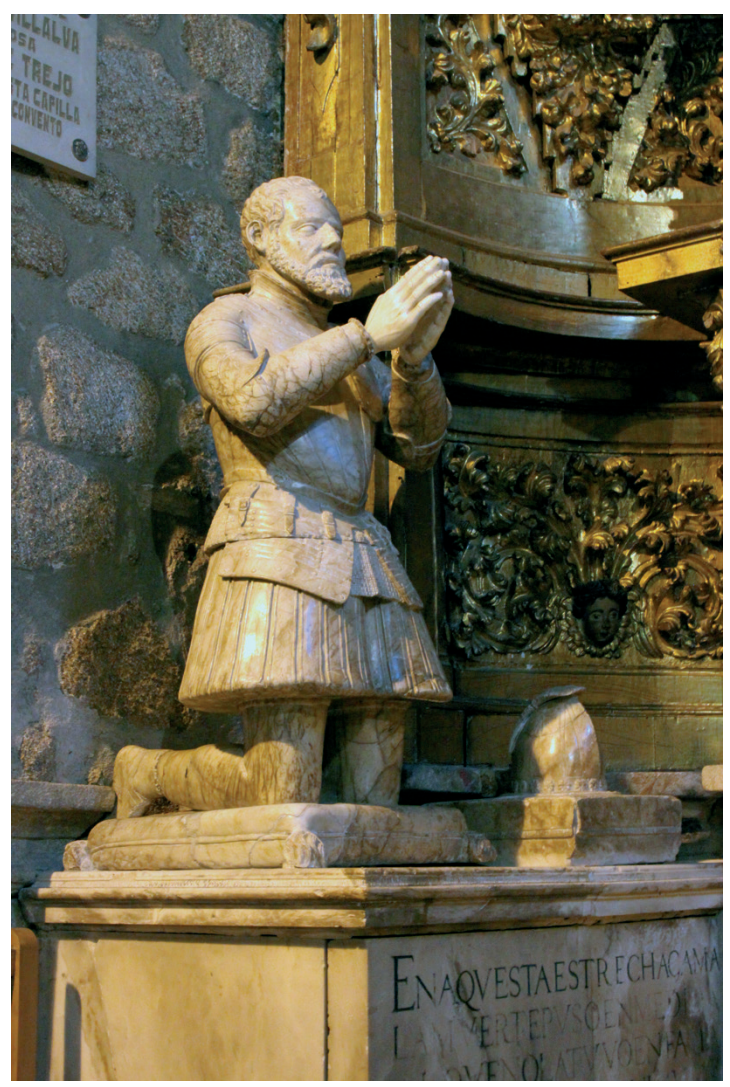

Fig. 6. Plasencia, convento de San Ildefonso, escultura orante del coronel don Cristóbal de Villalba $(\uparrow 1516)$, realizada en 1596.

que le permitió emparentar con los linajes Trejo y Carvajal tras desposar a doña Estefanía de Trejo y de la $\mathrm{Cerda}^{73}$.

La muerte le sorprendió en Estella en 1516, donde sus restos fueron inhumados y trasladados posteriormente a la capilla mayor del convento de San Ildefonso, del que era patrono junto a su mujer ${ }^{74}$. El mayorazgo que el rey Fernando le había autorizado a instituir en 1512 -poco antes de culminar su valerosa actuación en la conquista de Navarra- fue heredado por su primer hijo varón, Juan. Y como era habitual en la época, el segundón Pedro Bermúdez de Villalba, aún de corta edad a la muerte de su padre ${ }^{75}$, se decantó finalmente por la carrera religiosa, en la que alcanzó la chantría de la catedral de Plasencia ${ }^{76}$ en $1553^{77}$-que ya había ocupado su tío paterno

73 Fernández, 1627: 39, 174-179. Gómez Vozmediano, 2012: 191-195; en este trabajo se recoge la bibliografía sobre el coronel.

${ }^{74}$ Fernández, 1627: 179. Real Academia de la Historia (RAH). Col. Pellicer, Ms. 1630, t.XVI, 9/4070, ff. 103v104r. Sánchez Loro, 1956: 37, 44.

75 Los datos citados en Gómez Vozmediano, 2012: 192, 196, 200-201.

76 Fernández, 1627: 176.

77 Díaz y Pérez, 1884: II, 478. 
Juan- y el priorato del convento dominico de San Vicente ${ }^{78}$-cuyas funciones pudo desempeñar nombrando un coadjutor para la chantría ${ }^{79}$.

No es casual que don Pedro Bermúdez hiciera el sepulcro para enterrar a su padre el mismo año en el que Álvarez construía el túmulo de la marquesa de Mirabel. En su ánimo debía albergar la intención de emular el conjunto funerario que, también en esas mismas fechas, se estaba construyendo el bailío fray Martín Nieto en el convento cuyo priorato había detentado, y lograr así la eternidad para quien acumuló fama en vida gracias a sus gestas guerreras; no olvidemos que don Pedro había iniciado su carrera militar antes de inclinarse por la Iglesia, llegando a incoar en 1548 el título de caballero alcantarino ${ }^{80}$, precisamente cuando don Luis de Ávila y Zúñiga, II marqués de Mirabel, era comendador de la Orden - cargo al que accedió en $1546^{81}$. Para ejecutar el "luzillo y estatua de mármol de rodillas" que dispuso "al lado del evangelio" 82 , es lícito pensar que el chantre acudiera al artista que en ese momento estaba trabajando para su Orden; Juan Álvarez era además el aparejador de la catedral de Plasencia, a la que don Pedro llevaba vinculado desde 1553, y de cuyo cabildo era patrono ${ }^{83}$; para él debía de ser un artista de confianza, al que acudiría para encargarle no solo el sepulcro de sus padres, sino también el cometido de preparar el lugar donde habría de enterrarse junto a ellos, según dispuso en su testamento de 8 de septiembre de $1596^{84}$. La pertenencia del chantre a la familia Trejo-Carvajal también avala nuestra hipótesis; su madre, doña Estefanía de Trejo y de la Cerda, fue hermana de don Luis de la Cerda, de quien partió la línea sucesoria conducente hasta doña Inés de Vargas y Camargo ${ }^{85}$, contemporánea suya, y para cuyo entierro y el de su marido Álvarez daría trazas en 1607.

Como ya observara Mélida, el sepulcro sufrió una profunda remodelación ${ }^{86}$ entre 1727 y 1729, siendo titular del mayorazgo el VII marqués de Cardeñosa; la intervención consistió en desplazar parte del mausoleo para que éste no quedara oculto tras el nuevo retablo que se construyó en el presbiterio, de mayores dimensiones que el anterior ${ }^{87}$. El sepulcro se redujo a la urna sobre la que va situada la escultura y sirve de marco a la inscripción ${ }^{88}$; en la carta que la abadesa, doña Josefa de Paredes y Bedoya, remitió al mayorazgo el 24 de agosto de 1728 para dar cuenta de las reformas acometidas en el monasterio, consta que la obra ya estaba prácticamente terminada, y que el entierro, "sin parecerse al legado [...] esta dizente[,] estando mas levantado con mayor autoridad" 89 .

Según el "testimonio de el rotulo i epitafio y armas" del mausoleo de $1739^{90}$, sabemos que la congregación trató de emular el conjunto original y paliar los efectos de la remodelación: el escudo del coronel - del que existe un dibujo en la colección Pellicer (fig. 7) ${ }^{91}$ - se pintó sobre la pared del fondo, junto a una inscripción donde constaba que doña Estefanía también fue enterra-

${ }^{7}$ RAH.Pellicer, Ms. 1630, t.XVI, 9/4070, f.104v.

79 Así consta en el pleito que Mateo de la Pila le puso en 1591 sobre la posesión de la chantría, tras la muerte de su coadjutor Francisco de Miranda. Archivo de la Real Chancillería de Valladolid, Pleitos Civiles, Pérez Alonso (OLV), caja 1284 , exp. 23 , s.f.

${ }^{80}$ AHN.OOMM, Caballeros de Alcántara, exp. 185, s.f., donde consta como Pedro Bermúdez de Villalba y Trejo González de Chaves y González de Carvajal.

81 Mateos Calvo, 2015: 14.

82 RAH.Pellicer, Ms. 1630, t.XVI, 9/4070, f.104r.

83 RAH.Pellicer, Ms. 1630, t.XVI, 9/4070, f.104r.

${ }^{84}$ ACP, leg. 269, exp. 44, s.f.: dispuso su sepultura "[...] en la capilla de mis señores Padres que estan sepultados en la bobeda que yo e echo [...]".

85 Salazar y Castro, 1697: 439-440. RAH.Salazar y Castro, 9/296, f.178v.

86 Mélida y Alinari, 1924: II, p. 316.

87 Gómez Vozmediano, 2012: 212.

88 Redondo Cantera, 1987: 279 (inscripción) y 256, 266 (análisis del epitafio).

89 AHN.Nobleza, Luque, C.393, D.571, s.f.

90 AHN.Nobleza, Luque, C.160, D.17, f.1r.

91 RAH.Pellicer, Ms. 1630, t.XVI, 9/4070, f.93r. 
da con su esposo 92 ; ésta debía proceder del friso que habría sustentado el frontón con la heráldica del titular, ahora recreada sobre la pared. Ambos elementos, escudo e inscripción, debieron desaparecer cuando se reparó el sepulcro en 1877 para tratar de paliar los daños ocasionados por las tropas napoleónicas, responsables también de la mutilación de las manos que sufrió la escultura; éstas se le pusieron nuevas en ese mismo año, de mármol y bastante desproporcionadas ${ }^{93}$. Mélida ya vio un escudo y un rótulo modernos ${ }^{94}$, y hoy solo perdura éste último.

El coronel se representa orante y de rodillas sobre un almohadón -la escultura está ejecutada en dos bloques de mármol-. Ciñe media armadura, con gorjal, peto y espaldar, escarcelas y cota de malla; viste calzas y gregüescos o trusas acuchilladas y ajustadas a la mitad del muslo. A su izquierda, sobre un escabel, su capacete con los cordobanes cuidadosamente doblados. Fue representado a edad madura, con gesto noble, el pelo con rizos y mechones, barbado y la nariz algo aguileña. Es un retrato realizado con corrección y calidad. La obra hay que ponerla en relación con la escultura de fray Martín Nieto, que debía ser

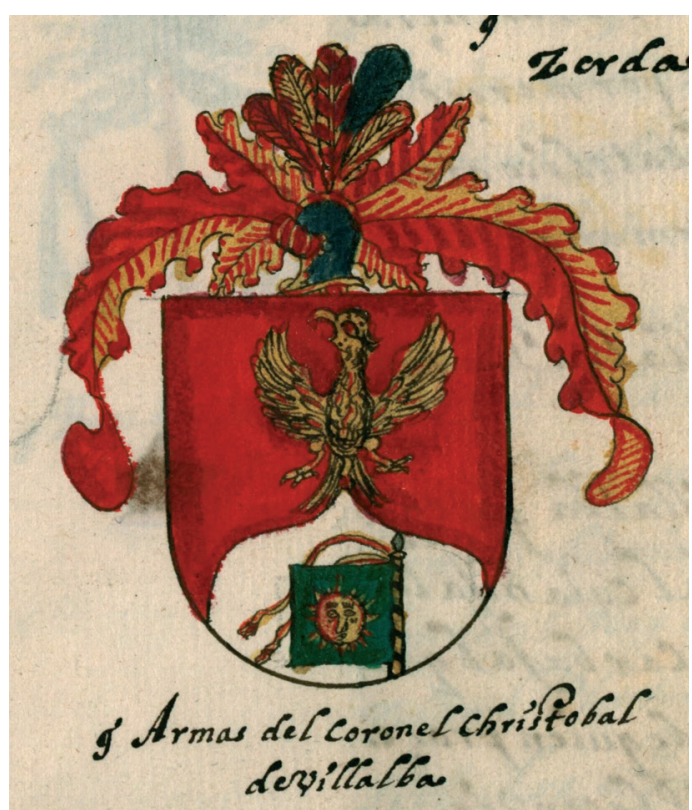

Fig. 7. Escudo del coronel don Cristóbal de Villalba, similar al que debía timbrar su sepulcro en el convento placentino de San Ildefonso. Real

Academia de la Historia, Colección Pellicer, Ms.1630, t.XVI, 9/4070, f.93r. (C) Real Academia de la Historia. muy similar a ésta.

\section{El sepulcro del obispo don de Pedro de Carvajal Girón (†1621)}

El último sepulcro que diseñó Juan Álvarez en la ciudad de Plasencia fue para el obispo don Pedro de Carvajal Girón, quien dispuso su capilla funeraria en la iglesia donde había sido bautizado, la de San Nicolás ${ }^{95}$, donde su familia poseía además dos sepulturas "desde antiguo" 96. Consejero de Felipe II, canónigo y deán de la catedral de Toledo, y obispo de Coria (1604$1621)^{97}$, don Pedro procedía de uno de los linajes más fecundos de España, el de los Carvajales extremeños.

En virtud del protocolo que el obispo otorgó el 1 de enero de 1610, sabemos que había heredado de su hermano don Álvaro de Carvajal ${ }^{98}$, arcediano de Plasencia y capellán mayor y limosnero de Felipe III, los derechos sobre dicha capilla, que don Pedro se obligaba a "edificar y acabar en perfeccion [...] al sitio que cae debaxo de la torre junto a ella [...]", con su reja y adornos. Asimismo, tomaba a su cargo la dotación de las dos sepulturas que la familia tenía en la iglesia junto al altar de San Ansano, cuyos derechos heredaba su sobrino don Diego Esteban González de Carvajal, caballero de Santiago, regidor de Plasencia y comendador de Castroverde.

\footnotetext{
92 Gómez Vozmediano, 2012: 212.

93 Sánchez Loro, 1956: 46, 166-169.

94 Mélida y Alinari, 1924: II, p. 316.

95 González Dávila, 1647: 468.

96 BSMP, AJBCh, Capellanías y sepulturas en Plasencia y Casas y Calles de la misma. San Nicolás.

97 RAH.Pellicer, Ms. 1630, t.XVI, 9/4070, ff. 87r-87v.

98 El parentesco en Salazar y Castro, 1697: 462.
} 


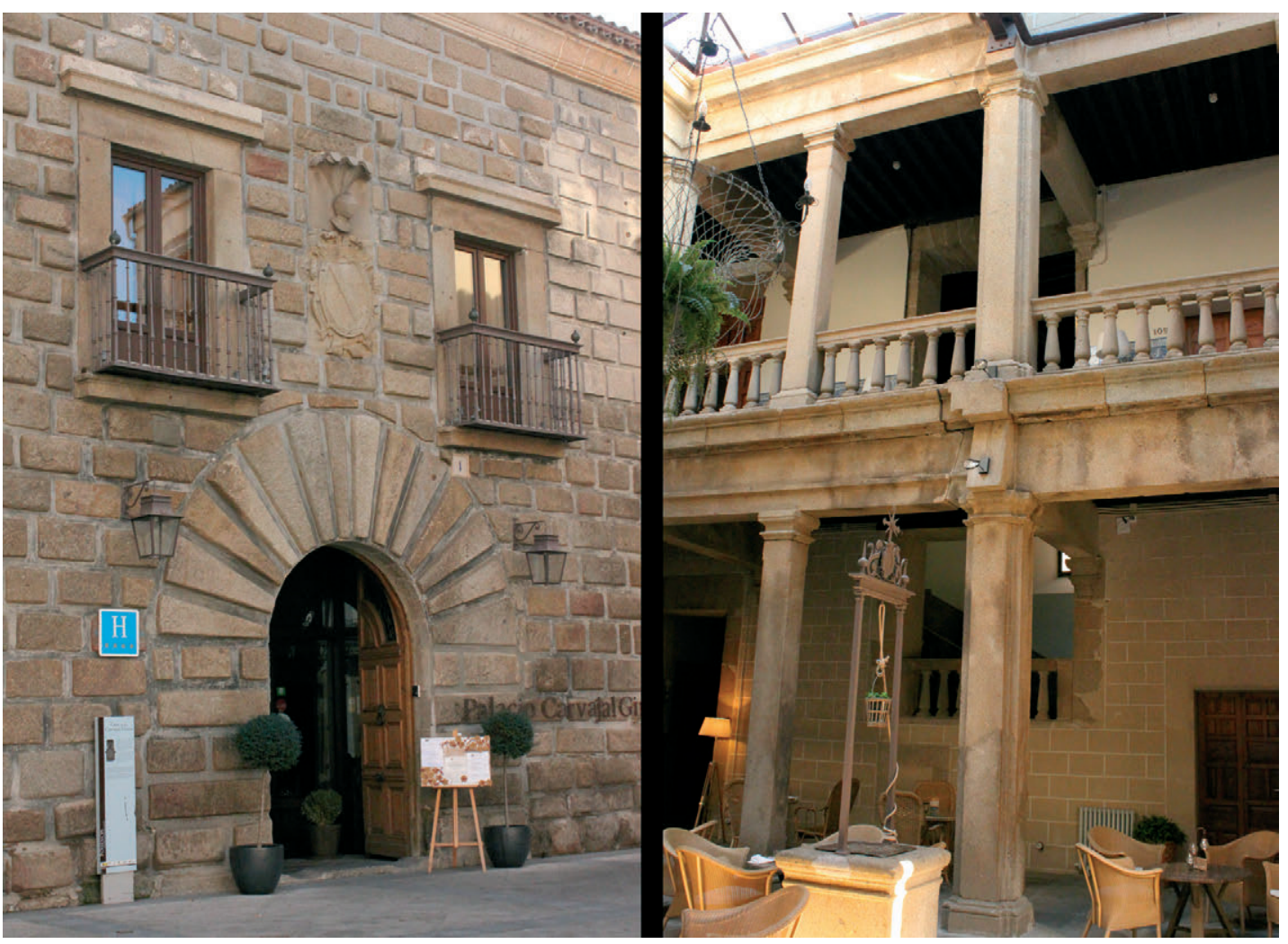

Fig. 8. Plasencia, palacio de la familia Carvajal-Girón. Trazas de Juan Álvarez, 1610.

En el mismo protocolo, el prelado también hizo constar que había mandado derribar "todo un quarto viejo hasta la calle de Trujillo en las casas principales" que don Diego tenía en la ciudad -el actual palacio de los Carvajal-Girón, situado en las inmediaciones de San Nicolás-, y que se había comenzado a construir conforme a "la traça y orden que tiene dado Juan Alvarez", "con un patio que a de auer, que llegará todo a ocho mile ducados poco más o menos"; a su conclusión se obligaba el obispo por el "mucho daño y perjuizio" que le causaría a don Diego en caso contrario ${ }^{99}$. Álvarez diseñó este palacio de Carvajal-Girón (fig. 8) bajo un sobrio estilo clasicista, con el orden toscano como protagonista frente al corintio que hasta entonces había utilizado, un giro que guarda plena relación con los elementos arquitectónicos diseñados para la capilla funeraria que nos ocupa (fig. 9).

Don Pedro de Carvajal debía conocer bien al maestro que contrató para las obras "del quarto viejo". El año anterior de 1609 había mediado para que el vicario de Coria designara a Juan Álvarez para dictaminar sobre las obras del convento de Nuestra Señora de la Concepción, en Cáceres ${ }^{100}$, que se había fundado bajo su prelatura y estaba "sugeto a la Dignidad" episcopal ${ }^{101}$. Y a él debió acudir para encargarle las trazas de su capilla y escultura orante, aprovechando que el artista trabajaba en esos momentos para él; el precio, unido al coste de los ornamentos para las sepulturas familiares, se estimó en 7.000 ducados ${ }^{102}$. Esta hipótesis sobre la autoría del conjunto funerario fue planteada en su momento por Tomás Pulido (1896-1978) y publicada en

\footnotetext{
99 Pulido y Pulido, 1980: 57. AHPCC.PN, Cáceres, Juan Romero, leg. 4256, ff. 17r-17v, 18v.

100 Pulido y Pulido, 1980: 58-61 y 535-539.

101 Fernández, 1627: 324-325.

102 Pulido y Pulido, 1980: 57. AHPCC.PN, Cáceres, Juan Romero, leg. 4256, f.17v.
} 
Fig. 9. Plasencia, iglesia de San Nicolás, entrada a la capilla funeraria del obispo de Coria don Pedro de Carvajal Girón. Trazas de Juan Álvarez, c.1610; realizada entre 1610 y 1615.

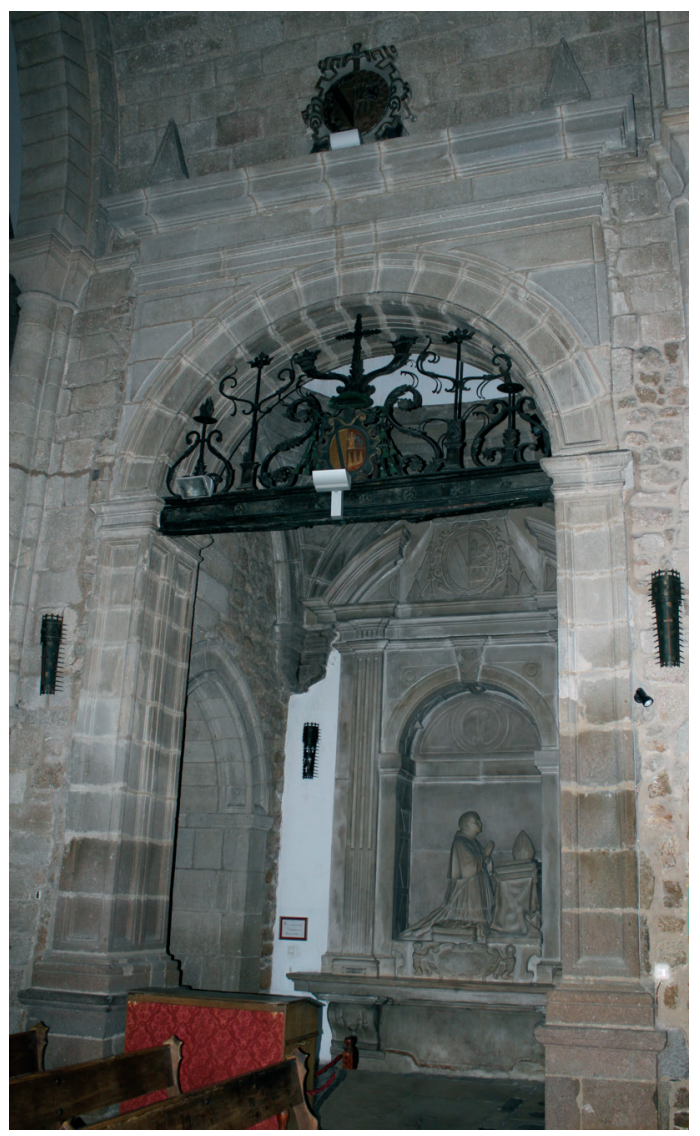

$1980^{103}$, pero ha pasado desapercibida para la crítica histórico-artística; se corrobora a partir de las trazas que Álvarez tenía diseñadas en 1607 para ejecutar los citados "bultos" de Santa Clara, uno de cuyos titulares, doña Inés de Vargas, estaba además vinculada al linaje de los Carvajales extremeños ${ }^{104}$.

Una vez trazado el conjunto, dieron comienzo las obras de la capilla, en las cuales se hallaba inmerso Juan Álvarez cuando se vio sorprendido por la enfermedad que declaraba tener en su testamento de 13 de diciembre de $1613^{105}$, y a raíz de la cual debió morir a finales de ese mismo año.

Ante esta nueva circunstancia, don Pedro de Carvajal se vio obligado a contratar la ejecución material de su escultura orante con Andrés Francisco, maestro de cantería vecino de Estremoz, villa del entonces unido a España reino de Portugal. En virtud de la carta de aprobación que el obispo firmó el 4 de agosto de 1613, sabemos que el contrato se había escriturado en Badajoz, entre don Hernando de Mena, provisor y vicario del obispado pacense, y el citado Andrés Francisco - prácticamente un desconocido para la historiografía- con fecha de 30 de junio de dicho año 1613, según el cual éste se comprometía a ejecutar "un entierro [...] y bulto" a cambio de 1.000 ducados que se entregarían del siguiente modo: 500 cuando estuviera labrada la escultura y lo restante "por el mes de junio de 1615", fecha para la que se estimaba que hubieran conclui-

\footnotetext{
103 Pulido y Pulido, 1980: 57.

104 Salazar y Castro, 1697: 461-462. Mayoralgo y Lodo, 1991: 340, nota 160.

105 AHPCC.PN, Plasencia, Pedro González Cidoncha, leg. 1068, s.f.
} 


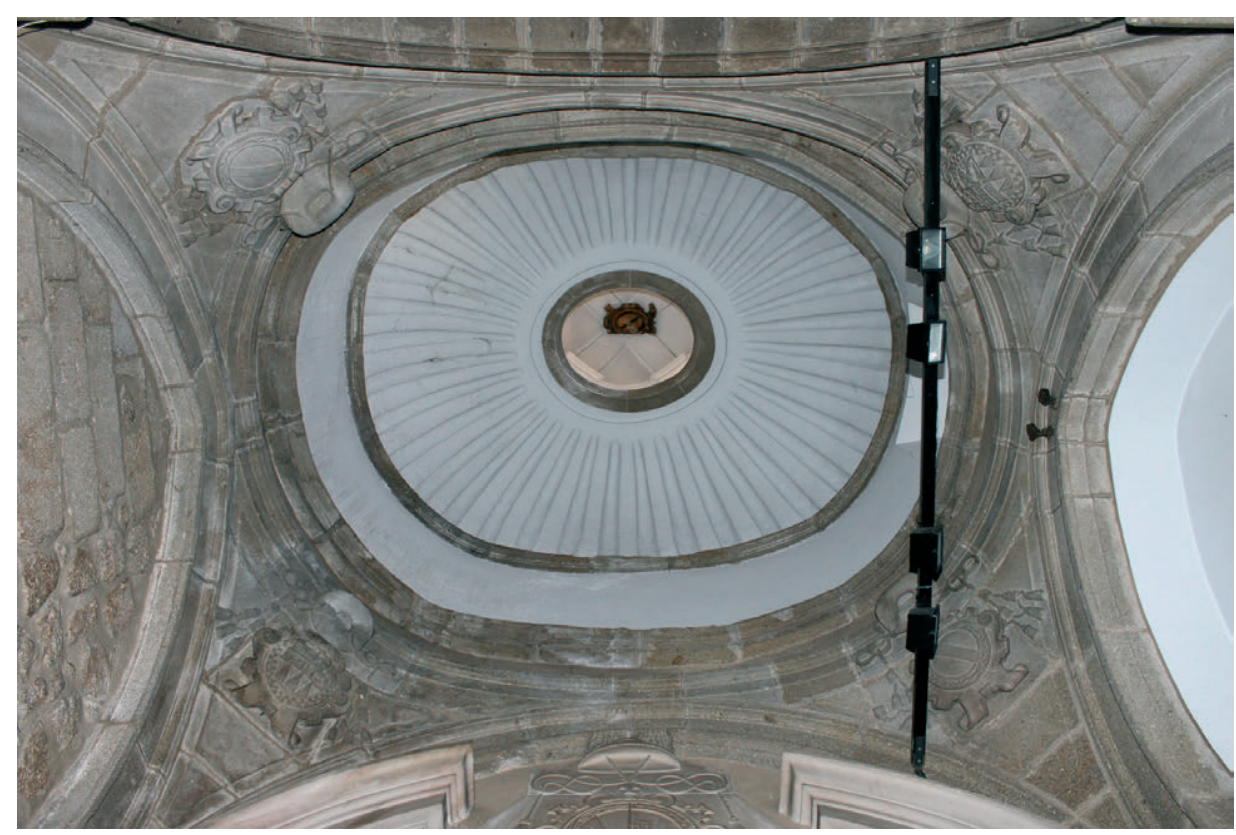

Fig. 10. Plasencia, iglesia de San Nicolás, bóveda elíptica de la capilla funeraria del obispo de Coria don Pedro de Carvajal Girón. Trazas de Juan Álvarez, c.1610; realizada entre 1610 y 1615.

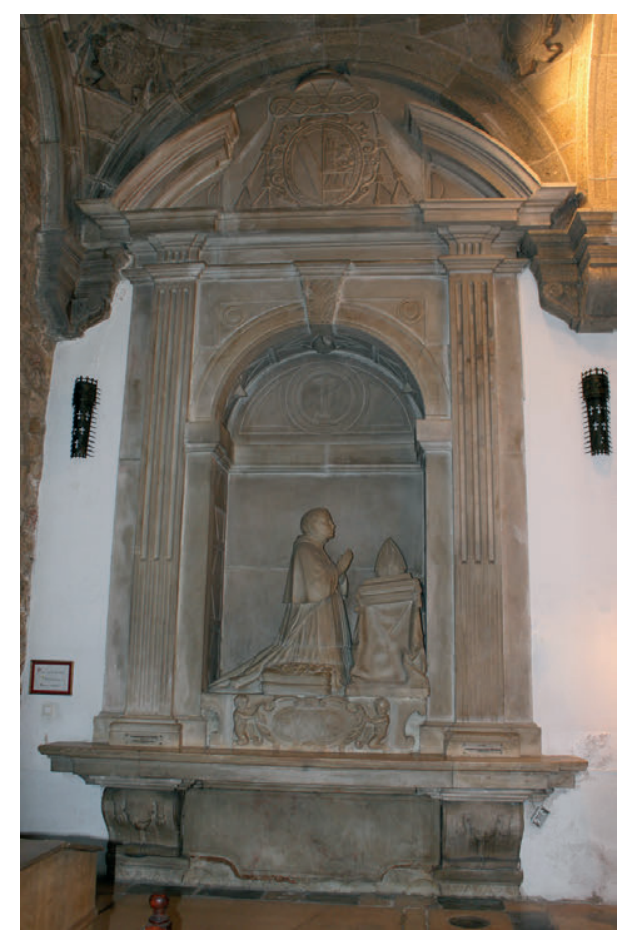

Fig. 11. Plasencia, iglesia de San Nicolás, sepulcro del obispo de Coria don Pedro de Carvajal Girón. Trazas de Juan Álvarez, c.1610; realizada entre 1610 y 1615 .

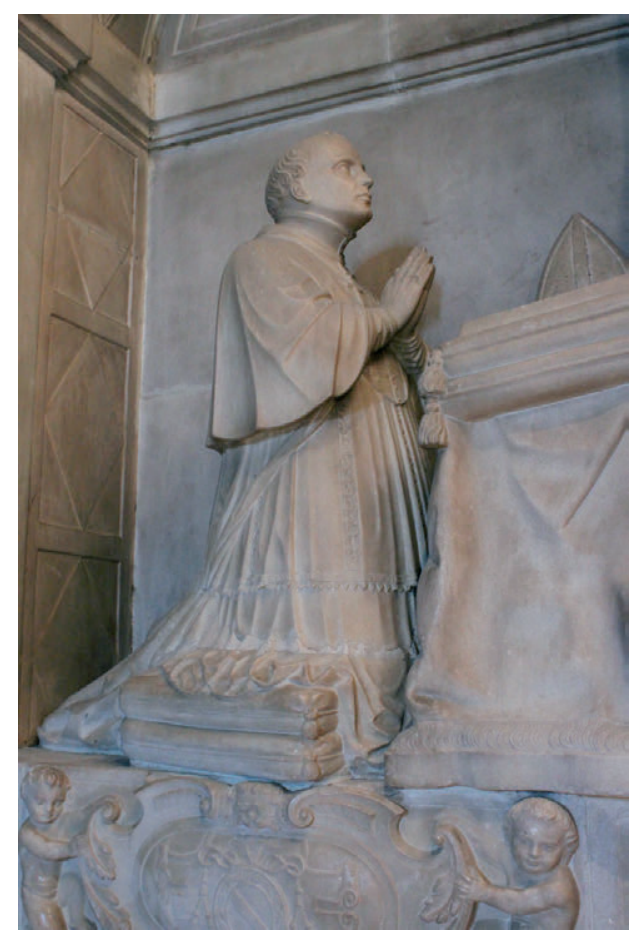

Fig. 12. Plasencia, iglesia de San Nicolás, escultura orante del obispo de Coria don Pedro de Carvajal Girón. Trazas de Juan Álvarez, c.1610; realizada entre 1610 y 1615 . Andrés Francisco fue el ejecutor material de las trazas en 1613, en lo que respecta a la escultura orante. 
do los trabajos de la capilla ${ }^{106}$, en la que debieron continuar laborando los oficiales de Juan Álvarez. El importe de la arquitectura, incluidas las trazas, debió ascender, pues, a la cuantía de 6.000 ducados.

La capilla funeraria se sitúa al lado de la torre, junto al presbiterio por el costado del Evangelio. Es de bella traza clásica, planta rectangular y cúpula elíptica gallonada (fig. 10); apea ésta sobre pechinas con los escudos del finado, sustentadas sobre ménsulas-triglifo. El ingreso se practica a través de un gran arco de medio punto de severa arquitectura clasicista, con la rosca cajeada al igual que las pilastras que flanquean el acceso. La reja a la que se aludía en la escritura de 1610 cierra el mausoleo; se decora con motivos del primer Renacimiento.

En el muro norte se sitúa el sepulcro, trazado a modo de arcosolio (fig. 11). Éste se eleva sobre unos modillones curvos y ornados con testas leoninas, que flanquean la placa que iría destinada a recibir la inscripción funeraria, y que finalmente se dispuso en el zócalo del muro oriental. Dos pilastras acanaladas de orden toscano arrancan del banco, y sirven de asiento para el friso y el frontón curvo partido que remata la obra con la heráldica del obispo. Las referidas pilastras enmarcan a su vez un nicho abierto en arco de medio punto, decorado con molduras y motivos placados en el fondo, que se repiten en el intradós del arco.

La escultura funeraria (fig. 12) es obra de extraordinaria calidad. Revestido de pontifical, don Pedro se representa orante y arrodillado sobre unos almohadones, junto a un reclinatorio cubierto con paño, en el que se disponen -sobre dos cojines- la mitra y un libro abierto. Destacan la cabeza y las manos, verdaderos estudios del natural; y el retrato que hace el cantero, aunque idealizado. El escudo Carvajal entre puttis tenantes sirve de asiento a la obra.

\section{BIBLIOGRAFÍA}

Andrés, Gregorio de (1972): Inventario de documentos sobre la construcción y ornato del Monasterio del Escorial existentes en el Archivo de su Real Biblioteca. Madrid: Anejo de Archivo Español de Arte. CSIC.

Barrio Loza, José Ángel/Moya Valgañón, José Gabriel (1981): “Los canteros vizcaínos (1500-1800): Diccionario Biográfico. II parte". En: Kobie, 11, Bilbao, pp. 173-282.

Beltrán de Heredia, Vicente (1972): Miscelánea Beltrán de Heredia. Colección de artículos sobre historia de la teología española. Salamanca: Editorial OPE, T. ${ }^{o}$ II.

Benavides Checa, José (1907): Prelados placentinos. Notas para sus biografias y para la Historia documental de la Santa Iglesia Catedral y Ciudad de Plasencia. Plasencia: ed. del autor.

Cadenas y López, Ampelio Alonso de/Barredo de Valenzuela y Arrojo, Adolfo (2003): Nobiliario de Extremadura. Madrid: Ed. Rev. Hidalguía, vol. 8.

Díaz y Pérez, Nicolás (1884): Diccionario histórico, biográfico, crítico y bibliográfico de autores, artistas y extremeños ilustres. Madrid: Perez y Boix Eds., 2 vols.

Fernández, Fray Alonso (1627): Historia y Anales de la Civdad y Obispado de Plasencia. Madrid: Iuan Gonçalez.

García Mogollón, Florencio Javier (1984): "El sepulcro del obispo de Coria D.Pedro de Carvajal Girón en la placentina iglesia de San Nicolás. Una obra del escultor portugués Andrés Francisco". En: Norba-Arte, V, Cáceres, pp. 141-162.

González Dávila, Gil (1647): Teatro eclesiástico de las Iglesias Metropolitanas, y Catedrales de los Reynos de las dos Castillas. Madrid: Pedro de Horna y Villanueva.

González Echegaray, María del Carmen/Aramburu-Zabala, Miguel Ángel/Alonso Ruiz, Begoña/Polo Sánchez, Julio Juan (1991): Artistas cántabros de la Edad Moderna. Su aportación al arte hispánico (diccionario biográfico-artístico). [Santander]: Institución Mazarrasa, Universidad de Cantabria.

Gómez Vozmediano, Miguel Fernando (2012): "Entre Plasencia y Estella: el rastro documental del coronel Cristóbal de Villalba en el Archivo de la Nobleza". En: Huarte de San Juan. Geografia e Historia, 19, Pamplona, pp. 187-212.

Lobo, Félix (2008): Parador de Plasencia. Antiguo convento de San Vicente Ferrer. En: <http://www.parador.es/sites/ default/files/parador/adjuntos/2013/08/plasencia_iglesiadesanvicenteferrer_0.pdf> [30/10/2015].

López, Juan (1613): Tercera parte de la Historia General de Sancto Domingo, y de sv Orden de Predicadores. Valladolid: Francisco Fernández de Cordoua.

López Martín, Jesús Manuel (1993): Paisaje urbano de Plasencia en los siglos XV y XVI. Mérida: Asamblea de Extremadura.

López de Haro, Alonso (1622): Nobiliario Genealogico de los Reyes y Titvlos de España. Madrid: Luis Sánchez, 2 vols.

106 García Mogollón, 1984: 156-157; 150-156 (descripción), 154 (inscripción). 
Llaguno y Amirola, Eugenio (1829): Noticias de los arquitectos y arquitectura de España desde su restauración. Madrid: Impr. Real, 4 vols.

Martín González, Juan José (1988): “Bienes artísticos de don Rodrigo Calderón”. En: BSAA, LIV, Valladolid, pp. 267308.

Martínez Verón, Jesús (2000): Arquitectos en Aragón. Diccionario histórico. Vol. I. Abad-Buzales. Zaragoza: Institución "Fernando el Católico" y Dip. Provincial.

Mateos Calvo, Jerónimo (2015): Luis de Ávila y Zúñiga. Marqués de Mirabel. Sevilla: Punto Rojo Libros.

Mayoralgo y Lodo, José Miguel de (1991): La Casa de Ovando (Estudio Histórico-Genealógico). Cáceres: Real Academia de Extremadura.

Mélida y Alinari, José Ramón (1924): Catálogo Monumental de España. Provincia de Cáceres. Madrid: Ministerio de Instrucción Pública y Bellas Artes, 3 vols.

Méndez Hernán, Vicente (2004): El retablo en la diócesis de Plasencia. Siglos XVII y XVIII. Cáceres: Universidad de Extremadura.

Montero Aparicio, Domingo (1977): “La iglesia parroquial de Malpartida de Plasencia y su retablo mayor". En: Revista de Estudios Extremeños, XXXIII, 1, Badajoz, pp. 181-198.

Navareño Mateos, Antonio (1988): Aportaciones a la historia de la arquitectura en Extremadura. Repertorio de artistas y léxico de alarifes. Cáceres: Universidad de Extremadura.

Navareño Mateos, Antonio/Sánchez Lomba, Francisco Manuel (1989): "Vizcaínos, trasmeranos y otros artistas norteños en la Extremadura del siglo XVI". En: Norba-Arte, IX, Cáceres, pp. 7-13.

Paredes y Guillén, Vicente (1909): Los Zúñiga, señores de Plasencia. Cáceres: Tip., Enc. y Lib. de Jiménez.

Parrado del Olmo, Jesús María (1981): Los escultores seguidores de Berruguete en Palencia. Valladolid: Univ. de Valladolid.

Pescador del Hoyo, María del Carmen (1959): "El maestro Juan Álvarez y la escalera del aire de Plasencia”. En: Revista de Estudios Extremeños, XV, 2, Badajoz, pp. 397-404.

Ponz, Antonio (1778 y 1784²): Viage de España. Madrid: Joachin Ibarra, T. ${ }^{\circ}$ VII, $1 .^{\text {a }}$ y $2 .^{\text {a }}$ eds.

Prieto Cantero, Amalia (1963): "Inventario razonado de los documentos referentes al monasterio de El Escorial existentes en la sección de Casa y Sitios Reales del Archivo General de Simancas”. En: Revista de Archivos, Bibliotecas y Museos, LXXI, Madrid, pp. 7-127.

Pulido y Pulido, Tomás (1980): Datos para la historia artística cacereña. Cáceres: Dip. Provincial.

Redondo Cantera, María José (1987): El sepulcro en España en el siglo XVI. Tipología e iconografía. Madrid: Ministerio de Cultura.

Rodríguez G. de Ceballos, Alfonso (1968): "El antiguo noviciado de los jesuitas en Madrid". En: Archivo Español de Arte, XLI, 164, Madrid, pp. 245-265.

Rodríguez G. de Ceballos, Alfonso (1976): “Juan Moreno y la arquitectura protobarroca en Salamanca”. En: Archivo Español de Arte, XLIX, 195, Madrid, pp. 247-271.

Rodríguez G. de Ceballos, Alfonso (1987): La iglesia y el convento de San Esteban de Salamanca. Salamanca: Centro de Estudios Salmantinos.

Rosado, Joaquín (1906): Guía de la ciudad de Plasencia (Cáceres) y su partido judicial. Año II-1906. Plasencia: Farmacia de Rosado.

Salazar y Castro, Luis de (1697): Historia Genealogica de la Casa de Lara, t.III. Madrid: Impr. Real.

Sánchez Lomba, Francisco Manuel (1994): Iglesias caurienses del mil quinientos. Cáceres: Dip. Provincial.

Sánchez Lomba, Francisco Manuel/García Bacas, María Isabel (1988): "Nueva aportación a la obra de Pedro de Ybarra en Extremadura: la iglesia parroquial de Miajadas”. En: Norba-Arte, VIII, Cáceres, pp. 39-57.

Sánchez Loro, Domingo (1956): El convento placentino de San Ildefonso. Cáceres: Dpto. Prov. de Seminarios de FET y de las JONS.

Fecha de recepción: 25-I-2016

Fecha de aceptación: 19-V-2016 